\title{
BIO-CHAR SEQUESTRATION IN TERRESTRIAL ECOSYSTEMS - A REVIEW
}

\author{
JOHANNES LEHMANN ${ }^{1, *}$, JOHN GAUNT $^{2}$ and MARCO RONDON ${ }^{3}$ \\ ${ }^{1}$ Department of Crop and Soil Sciences, College of Agriculture and Life Sciences, Cornell \\ University, Ithaca, NY 14853, USA ${ }^{2}$ GY Associates Ltd., Harpenden, Herts, AL5 2DF, UK; \\ ${ }^{3}$ Climate Change Program, Centro Internacional de Agricultura Tropical (CIAT), Cali, Colombia \\ (*Author for correspondence,E-mail:CL273@cornell.edu)
}

\begin{abstract}
The application of bio-char (charcoal or biomass-derived black carbon (C)) to soil is proposed as a novel approach to establish a significant, long-term, sink for atmospheric carbon dioxide in terrestrial ecosystems. Apart from positive effects in both reducing emissions and increasing the sequestration of greenhouse gases, the production of bio-char and its application to soil will deliver immediate benefits through improved soil fertility and increased crop production. Conversion of biomass $\mathrm{C}$ to bio-char $\mathrm{C}$ leads to sequestration of about $50 \%$ of the initial $\mathrm{C}$ compared to the low amounts retained after burning (3\%) and biological decomposition $(<10-20 \%$ after 5-10 years), therefore yielding more stable soil $\mathrm{C}$ than burning or direct land application of biomass. This efficiency of $\mathrm{C}$ conversion of biomass to bio-char is highly dependent on the type of feedstock, but is not significantly affected by the pyrolysis temperature (within $350-500{ }^{\circ} \mathrm{C}$ common for pyrolysis). Existing slash-andburn systems cause significant degradation of soil and release of greenhouse gases and opportunies may exist to enhance this system by conversion to slash-and-char systems. Our global analysis revealed that up to $12 \%$ of the total anthropogenic $\mathrm{C}$ emissions by land use change $(0.21 \mathrm{Pg} \mathrm{C})$ can be off-set annually in soil, if slash-and-burn is replaced by slash-and-char. Agricultural and forestry wastes such as forest residues, mill residues, field crop residues, or urban wastes add a conservatively estimated $0.16 \mathrm{Pg} \mathrm{C} \mathrm{yr}^{-1}$. Biofuel production using modern biomass can produce a bio-char by-product through pyrolysis which results in $30.6 \mathrm{~kg} \mathrm{C}$ sequestration for each GJ of energy produced. Using published projections of the use of renewable fuels in the year 2100, bio-char sequestration could amount to 5.5-9.5 $\mathrm{Pg} \mathrm{C} \mathrm{yr}^{-1}$ if this demand for energy was met through pyrolysis, which would exceed current

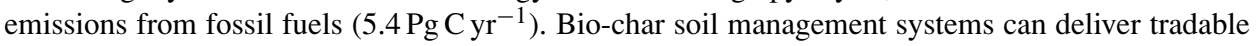
$\mathrm{C}$ emissions reduction, and $\mathrm{C}$ sequestered is easily accountable, and verifiable.
\end{abstract}

Keywords: black carbon, carbon sequestration, charcoal, emissions trading, global warming potential, greenhouse gas emissions, soils, terra preta de indio

\section{Introduction}

Climate change is one of the most important challenges facing the modern world. Temperature increases have now been unequivocally proven and are occurring with an unprecedented rate (IPCC 2001). Carbon dioxide $\left(\mathrm{CO}_{2}\right)$, methane $\left(\mathrm{CH}_{4}\right)$ and nitrous oxides $(\mathrm{NO} x)$ are important drivers of the anthropogenic greenhouse effect, which are released both through burning of fossil and biomass fuel as well as decomposition of above- and belowground organic matter. International efforts aim at reducing avoidable greenhouse gas emissions or off-setting unavoidable emissions through sequestration of $\mathrm{C}$ in the environment. As regards sequestration, 
many different strategies are discussed in the literature, ranging from wide-spread afforestation and reforestation in terrestrial ecosystems (IPCC 2000) to pumping of $\mathrm{CO}_{2}$ into deep ocean and geological layers (Marchetti 1977; DOE 1999). For terrestrial ecosystems it has been proposed that $\mathrm{C}$ sequestration can be increased by increasing soil C stocks (Batjes 1998; Izaurralde et al. 2001; Scholes and Noble 2001). Such a proposal is sensible given the fact that more than $80 \%$ of the terrestrial organic C stores are contained in soils (IPCC 2000). However, recent analyses urge caution, highlighting that efforts aimed to achieve $\mathrm{C}$ sequestration in soil are often off-set by other greenhouse gas emissions (Schlesinger 1999) and that soils generally show low potential to accumulate $\mathrm{C}$; for example, in conjunction with forest growth (Schlesinger 1990; Richter et al. 1999; Post and Kwon 2000; Schlesinger and Lichter 2001). The consensus appears to be that soil represents a finite $\mathrm{C}$ sink at best and will only provide a window of opportunity for reducing $\mathrm{C}$ emissions or exploring other opportunities for $\mathrm{C}$ sequestration (Freibauer et al. 2004; Lal 2004) and that these $C$ sinks may have a low permanency and can be easily depleted upon land use change (Rasmussen et al. 1998).

We propose a new approach to $\mathrm{C}$ sequestration in terrestrial ecosystems through the application of biomass-derived black $\mathrm{C}$ (charcoal, the popular misnomer for wood-char, or hereafter called "bio-char") to soil, which offers both a large and long-term $\mathrm{C}$ sink. The conversion of biomass to bio-char as a $\mathrm{C}$ sink has been proposed before (Seifritz 1993) but was not explicitly linked to an application to soil.

Land application of bio-char is not a new concept. For example, certain dark earths in the Amazon Basin (so-called Amazonian Dark Earths or "terra preta") have received large amounts of charred materials, the residues from biomass burning (Sombroek et al. 2003). These applications were most likely a result of both habitation activities and deliberate soil application by Amerindian populations before the arrival of Europeans (Erickson et al. 2003). Large amounts of bio-char derived $\mathrm{C}$ stocks remain in these soils today, hundreds and thousands of years after they were abandoned. The total $\mathrm{C}$ storage is as high as $250 \mathrm{MgCha}^{-1} \mathrm{~m}^{-1}$ compared to typical values of $100 \mathrm{MgC} \mathrm{ha}^{-1} \mathrm{~m}^{-1}$ in Amazonian soils derived from similar parent material (Glaser et al. 2001). Such C storage in soils far exceeds the potential $\mathrm{C}$ sequestration in plant biomass even if bare soil were, theoretically, restocked to primary forest containing about $110 \mathrm{Mg} \mathrm{Cha}^{-1}$ above ground (Sombroek et al. 2003).

Bio-char can act as a soil conditioner enhancing plant growth by supplying and, more importantly, retaining nutrients and by providing other services such as improving soil physical and biological properties (Glaser et al. 2002; Lehmann et al. 2003a; Lehmann and Rondon 2005). Field based experience of the benefits of land application for agricultural productivity are such that the financial benefits of application are not yet established. Further, bio-char application delivers environmental benefits. Establishing mechanisms by which the external environmental benefits can be monetized or internalized may be important to the adoption of bio-char 
technologies. These economic aspects as well as any social aspects are not resolved in this paper, beyond considering the implications of $\mathrm{C}$ emission trading, but are important for the successful implementation of a bio-char system and such studies should be conducted in the future. We will also not discuss other uses of bio-char such as filters or construction materials, which have a large potential as a $\mathrm{C}$ sink as demonstrated in Japan (Okimori et al. 2003). This contribution restricts itself to exploring the important and so far undocumented biological feasibility and the potential quantitative importance with respect to $\mathrm{C}$ sequestration in soil. The viability of such a bio-char management system depends on (i) the competing uses for the bio-char, and the biomass that it is produced from, and (ii) on environmental constraints. These are reviewed for the most important bio-char systems in the first part below. In the last section, we explore the implications for $\mathrm{C}$ emissions trading mechanisms in the context of a bio-char soil management system from a biological perspective.

\section{Mechanism and Quantification of Carbon Sequestration in Bio-Char Systems}

The most important opportunities to incorporate a bio-char soil management technique are in (i) shifting cultivation; (ii) charcoal production; (iii) recycling of agricultural wastes; (iv) energy production using renewable fuels (bio-fuels); and (v) cropping for bio-char using fast-growing trees. In all five systems, bio-char can be produced and applied to soil. Household, municipal or industrial wastes are not discussed here, because they may contain heavy metals or organic pollutants that pose the challenge of environmental contamination by land application of the bio-char (although bio-char produced from sewage sludge in Japan did not show harmful levels of heavy metals; Shinogi et al. 2003).

Conversion of biomass to bio-char fundamentally alters the transformation dynamics with respect to $\mathrm{C}$ sequestration. Upon charring approximately $50 \%$ of the $\mathrm{C}$ contained in the biomass is immediately released, leaving a stable bio-char residue (Figure 1A). Non bio-char material decomposing in soil will initially release $\mathrm{C}$ more slowly over time. However, release of $\mathrm{C}$ continues until almost all $\mathrm{C}$ is lost and can be estimated to be less than $10-20 \% \mathrm{C}$ remaining in agricultural soil after 5-10 years (depending on C quality and environment). Thus ultimately the bio-char application leads to considerably greater amounts of $\mathrm{C}$ remaining in soil than application of un-charred organic matter (Figure 1; Section 4). In a bioenergy system, the initial loss of $\mathrm{C}$ during charring can be used for energy production (Section 2.4; Figure 1A) and can off-set fossil fuel use (Section 6). In addition to the much greater longevity (Section 4), a key advantage of bio-char with respect to soil ecosystem functions is that it is more efficient in improving soil fertility and nutrient retention than un-charred organic matter (Sombroek et al. 1993; Lehmann and Rondon 2005). Here we consider land-based production systems in which bio-char management 

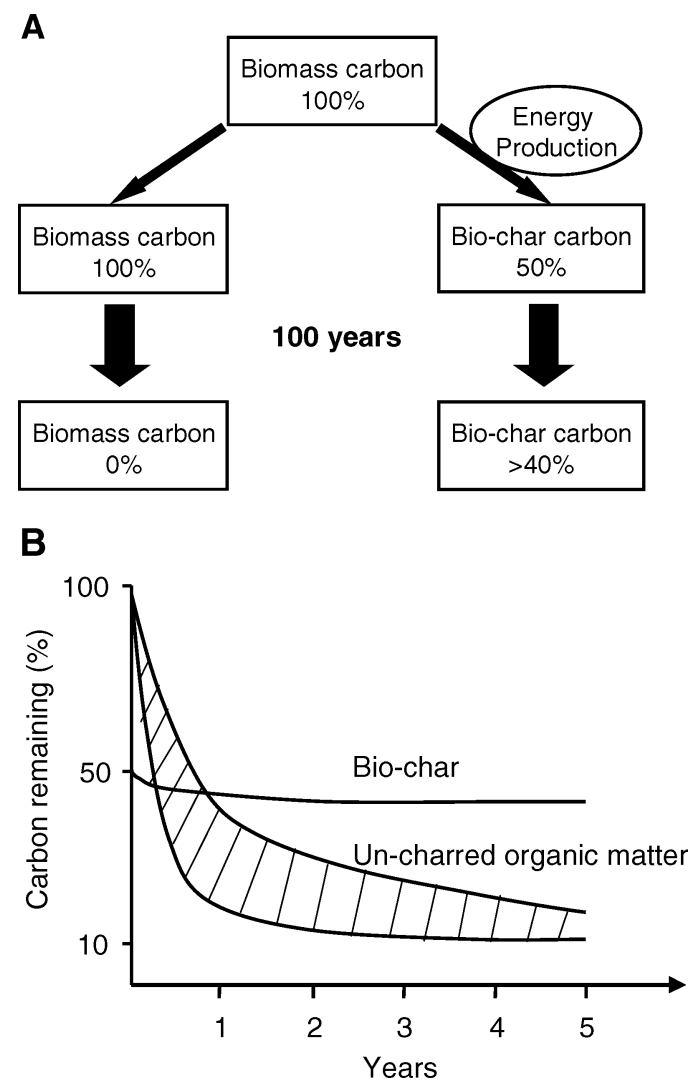

Figure 1. Schematics for biomass or bio-char remaining after charring and decomposition in soil. (A) C remaining from biomass decomposition after 100 years from IPCC (1996); C remaining after charring or pyrolysis (FAO 1983; Daud et al. 2001; Lehmann et al. 2002; Demirbas 2001 2004a; Katyal et al. 2003; Day et al. 2005); bio-char C remaining after decomposition see Section 4. (B) range of biomass $\mathrm{C}$ remaining after decomposition of crop residues from Jenkinson and Ayanaba (1977); estimation of bio-char decomposition see Section 4.

can be integrated from a biological perspective and examine the $\mathrm{C}$ sequestration potential in the context of the global $\mathrm{C}$ cycle.

\subsection{SHIFTING CULTIVATION}

Shifting cultivation is perceived as a traditional land use system primarily used in tropical ecosystems (Nye and Greenland 1960). Small-scale farmers slash the natural vegetation at varying stages of regeneration, or even primary forest to allow a crop to be grown. Under this system soil fertility declines rapidly and weed pressure increases. Once this leads to a deterioration in crop yield the land is left fallow to regenerate. Typical fallow periods in such a system range from 5-25 years, 
while cropping periods are 1-3 years long (Nye and Greenland 1960; Levasseur and Olivier 2000; Weisbach et al. 2002). Increasing population pressure results in greater proportions of forested land needing to be cropped under shifting cultivation and therefore in greater amounts of $\mathrm{CO}_{2}$ being released to the atmosphere from biomass and soil. A reduction of this substantial $\mathrm{CO}_{2}$ release (as land use change in the tropics, IPCC 2000: p. 4) which significantly contributes to the global $\mathrm{CO}_{2}$ evolution by land use change (Figure 2A), could be achieved through a bio-char soil management system. In most shifting cultivation systems, the natural vegetation is burned after slashing and between $38-84 \%$ of the biomass $\mathrm{C}$ in vegetation is released during the burn (Hughes et al. 2000). If this woody aboveground biomass were converted into bio-char by means of simple kiln techniques and applied to soil, more than $50 \%$ of this $\mathrm{C}$ would be sequestered in a highly stable form (FAO 1983: p. 28; Lehmann et al. 2002). For comparison, only about 3\% of the aboveground biomass would be converted into forms similar to bio-char (often called charcoal or biomass-derived black $\mathrm{C}$ in the respective literature) under a typical slash-and-burn system (Glaser et al. 2002). Five to $40 \mathrm{Mg} \mathrm{Cha}^{-1}$ can potentially be sequestered during each shifting cultivation cycle (Lehmann and Rondon 2005) in such a system that we can call "slash-and-char" (Lehmann et al. 2002). In 1980 it was estimated that 300 Mha were under shifting cultivation world-wide (US Interagency Task Force on Tropical Forests 1980; current values are most likely significantly greater but not available). With fallow periods of 5-25 years (using the relationship bio-char $=61.4\left(1-\mathrm{e}^{-0.015 \text { age }}\right)$ between bio-char and fallow age from Lehmann and Rondon 2005), this value indicates a potential for $\mathrm{C}$ sequestration of bio-char of 1.33-5.76 Pg C during each cycle. Uncertainties about the current and future extent of shifting cultivation warrant further investigation in order to provide more precise predictions. Assuming 2 years of cropping during each cycle followed by 5-25 years of fallow, the calculated amount of bio-char-C would be produced every 7-27 years, amounting to an annual production of 0.190-0.213 Pg C (Figure 2B). This would off-set $12 \%$ of the anthropogenic $\mathrm{C}$ emissions caused by land use change (1.7 $\mathrm{PgC}^{-1}$; IPCC 2001) and therefore offers a significant measure to mitigate climate change (Figure 2B). Additionally, the $\mathrm{CO}_{2}$ that was not emitted during the burn is sequestered in stable organic matter in soil, which can be increased through slash-and-char and a bio-char application to soil by $10 \%$ in 75 years (annual sequestration of $0.2 \mathrm{Pg} \mathrm{C}$ in relation to a current stock of $150 \mathrm{Pg} \mathrm{C}$ in stable SOM, Figure 2B). Under the conventional system unburnt plant residues are relatively labile and are largely mineralized to $\mathrm{CO}_{2}$ within months to only a few years depending on climate (Figure 1; Jenkinson and Ayanaba 1977).

The implementation of such a slash-and-char system is likely to be viable, as most farmers are intimately familiar with burning vegetation, and many subsistence farmers already engage in charcoal production to generate income (Coomes and Burt 2001). The charring step fulfills the same requirements as the normal burning (Ketterings et al. 1999) in that it clears the field from biomass that prohibits direct planting, it acts as a fertilizer, it improves structural properties of soil and reduces 

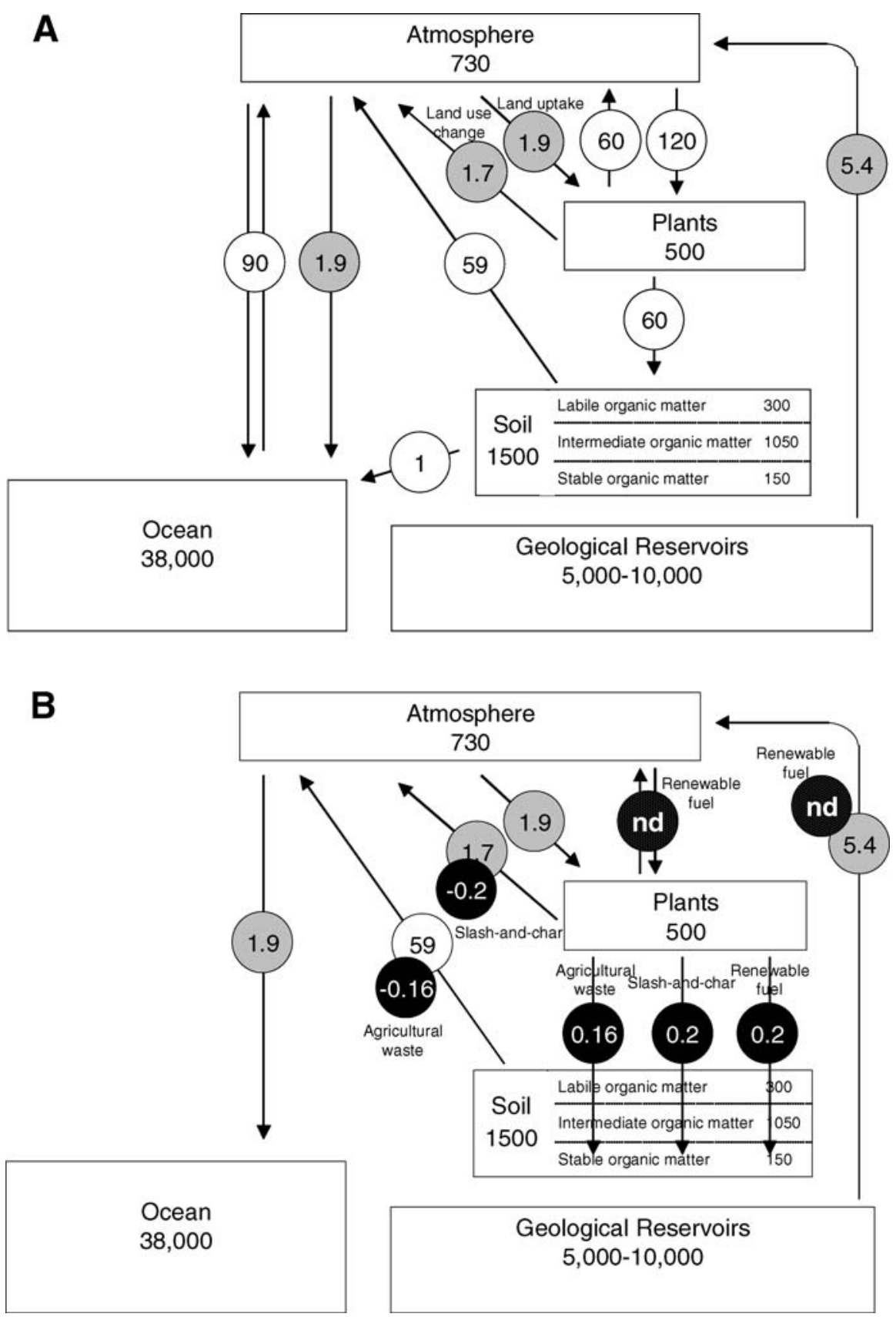

Figure 2. The global C cycle, the anthropogenic perturbation (IPCC 2001) (A) and the mitigation potential by bio-char soil management (from text) (B). nd is not determined future scenario (values discussed in text); fluxes (circles) in $\mathrm{PgC}^{-1}$ and stocks (boxes) in $\mathrm{PgC}$ (Pg is equivalent to $\mathrm{Gt}$ ); white denotes natural C fluxes, grey the anthropogenic perturbation today (both from IPCC 2001), black today's potential and black with white dots future projections for bio-char soil management. 
weed and pest problems. Charring can also be implemented after a normal burning, since most of the woody biomass is not burned, or only partially, and presents an obstacle for planting. In fact, many farmers start secondary fires to remove larger woody debris by piling them up before lighting (Ketterings et al. 1999). Therefore, converting such fire practices into in-field charring practices appears to be a small step for farmer adoption with few implications for labor requirements and uses the identical resources that were available to the farmer using slash-and-burn. Currently, no farm- or watershed-scale investigations exist that could establish a more robust basis for upscaling of emissions reductions and $\mathrm{C}$ sequestration by slash-and-char. This is an important challenge for future research.

\subsection{BIO-CHAR WASTES FROM “CHARCOAL" PRODUCTION}

World-wide, $41 \mathrm{Mt}$ of charcoal are produced annually for cooking and industrial purposes (FAO 2004). Most of this production is located in developing countries (40 Mt in 2002) rather than developed countries (1 Mt), with Africa being the highest producer (21 Mt) in comparison to South America (14 Mt) and Asia (4 Mt). Charcoal production is often detrimental to the environment, as it leads to deforestation and air pollution. Yet, most developing countries have few alternatives to charcoal production for household fuel. However, significant improvements are possible with viable alternatives as far as wood production, charcoal production with respect to human health and use of charcoal waste is concerned. Additionally, it has been argued that use of charcoal as a fuel replacing wood leads to lower levels of household indoor pollution and an associated reduction in mortality (Bailis et al. 2005). For industrial purposes and in large-scale commercial operations, options for clean and efficient charcoal production exist.

In many situations, only a portion of the charcoal produced for consumption is actually sold or used as fuel. A significant proportion of the individual charcoal pieces is too small in size to enter the market or be used in furnaces. In the following section, we concentrate on the improved use of these wastes from charcoal production. In many small-scale production systems, waste charcoal remains within the area of production or is discarded locally. The proportion of charcoal waste varies significantly depending on the production procedure, the wood properties, the charcoal processing, and the market demands (FAO 1983, 1991). For example, around Cali, Colombia, charcoal waste from local small-scale production for barbeque was determined to be $30 \%$ to $40 \%$ of the total production (Rondon unpubl.data). In some situations, a portion of this waste is sold to nurseries. Other sources report $20 \%$ fines remain from charcoal production using simple brick kilns (FAO 1991). For industrial purposes and from large-scale charcoal producers, charcoal waste accumulation is commonly much lower as production procedures are optimized to keep wastes low. In some instances, charcoal powder may be used for making briquettes and no charcoal waste accumulates. For a global budget, this proportion is assumed to be low, since most of the charcoal is produced in Africa typically 
with no opportunities to produce briquettes. As an estimate, charcoal waste of $20 \%$ calculates to $25 \%$ of the actual tradable charcoal, and with a world production of tradable charcoal $\left(41 \mathrm{Mt} \mathrm{yr}^{-1}\right)$ can be given as a C flux of $0.008 \mathrm{PgC}^{-1}$. This amount is low compared to global C fluxes (Figure 2). Charcoal wastes may, however, be of regional importance where small-scale producers dominate the market such as in most parts of Africa, in rural areas in South America and Asia.

Charcoal waste can be applied as bio-char to agricultural soils (including the fields where the trees are grown for charcoal production) and turned into a valuable resource for improving crop yields on acid and infertile tropical soils where nutrient resources are scarce (Lehmann and Rondon 2005). With relatively small amounts of $2-5 \mathrm{MgC} \mathrm{ha}^{-1}$ of bio-char, significant improvements of crop growth can be observed (Lehmann and Rondon 2005). The soil application of bio-char from charcoal wastes does not, however, constitute a net emission reduction or sequestration of $\mathrm{C}$, since the charcoal waste would accumulate whether it is applied to soil or not. However, if a switch to the use of charcoal leads to a substitution of fossil energy, the charcoal production as a whole would constitute an emissions reduction and the charcoal waste management would additionally be a net sequestration. This requires a sustainable production of feedstock through fast-growing trees and shrubs (avoiding soil degradation and off-site effects during wood production), minimization of air pollution, and prevention of health hazards for producers. An example for a successful emissions reduction through charcoal production is 'The Plantar Project' in Minas Gerais, Brazil, supported by the Prototype Carbon Fund of The World Bank (PCF 2003). This project achieves substitution of fossil coke energy for pig iron production through aforestation with eucalyptus and charcoal production. A net $\mathrm{C}$ sequestration can be achieved with such a project, if wastes of the charcoal production can be used for land application. Developing a sustainable charcoal production system is increasingly considered to be the most feasible and significant $\mathrm{C}$ sequestration strategy for example in regions with rapid $\mathrm{C}$ declines in soils such as Senegal (Liu et al. 2004).

\subsection{RECYCLING OF AGRICULTURAL AND FORESTRY WASTES}

In many agricultural and forestry production systems, waste is produced in significant amounts from crop residues such as (i) forest residues (logging residues, dead wood, excess saplings, pole trees); (ii) mill residues (lumber, pulp, veneers); (iii) field crop residues; or, (iv) urban wastes (yard trimmings, site clearing, pallets, wood packaging) (Walsh et al. 1999). Other industry and municipal residues could potentially be a suitable and quantitatively important source of bio-char (Malkow 2004), but are not considered here. Many of the forestry and agricultural residues can be used to produce bio-char and applied to agricultural soil both to sequester $\mathrm{C}$ and to improve the production potential of crops. In many cases, these waste materials have little value and their disposal incurs costs. Today large amounts (more than 50\% of total available residues in the U.S.; Walsh et al. 1999) can be 
TABLE I

Availability, suitability and global production of agricultural waste materials

\begin{tabular}{llll}
\hline Waste materials & Availability & Suitability & $\begin{array}{l}\text { Potential global production } \\
\text { of bio-char }\left(\mathrm{Pg} \mathrm{yr}^{-1}\right)\end{array}$ \\
\hline Forest residues & Medium & High & 0.04 \\
Mill residues & High & High & 0.05 \\
Rice husks & High & Medium & 0.04 \\
Groundnut shells & High & High & 0.002 \\
Urban waste & High & High & 0.03 \\
Total & & & 0.162 \\
\hline
\end{tabular}

acquired for less than $\$ 30$ per ton of biomass. The most suitable materials have high lignin concentration yielding the most bio-char (Demirbas 2004a) such as residues from sawmills, forest residues, or nut shells. Also the mineral content plays a role and woody biomass impregnated with $\mathrm{Na}, \mathrm{K}$, and $\mathrm{Ca}$ yielded up to $15 \%$ more bio-char than the original beech wood (Nik-Azar et al. 1997).

With a global accumulation of $70.3 \mathrm{Mm}^{3}$ wood residue for 2003 (FAO 2004), the total bio-char that would be available for $\mathrm{C}$ sequestration by using forestry residues amounts to $0.021 \mathrm{PgC} \mathrm{yr}^{-1}$ (Table I). Calculations were done using a density of wood residues of $0.11 \mathrm{Mg} \mathrm{m}^{-3}$ (Briggs 1994; mixture of sawdust, shaving and bark), a $\mathrm{C}$ concentration of $50 \%$, and a conversion from wood $\mathrm{C}$ to bio-char $\mathrm{C}$ of $53.5 \%$ (Lehmann et al. 2002). This value is probably an underestimate, since data from the U.S. alone (Walsh et al. 1999) suggest that an equivalent of $0.012 \mathrm{Pg} \mathrm{Cyr}^{-1}$ of bio-char could be produced from forest residues and $0.024 \mathrm{Pg} \mathrm{C} \mathrm{yr}^{-1}$ from mill residues. Therefore, the amount of bio-char that could be produced globally from forest residues is estimated at 0.04 (instead of the initial calculation of 0.021 from the FAO data alone) and mill residues at $0.05 \mathrm{Pg} \mathrm{Cyr}^{-1}$. The feasibility of such an approach has been demonstrated on a smaller scale with a sequestration of $62 \mathrm{Gg} \mathrm{C} \mathrm{yr}^{-1}$ of bio-char in an industrial tree plantation in Indonesia (Okimori et al. 2003). Other opportunities exist to utilize residues from pulp mills, from eucalyptus plantations to combat salinization and obtain eucalyptus oil, or as an alternative to garbage incineration (Ogawa et al. this issue). In the future, these waste materials may become a more valuable commodity as options and incentives for waste recycling or use to produce bioenergy will increase. Under the latter scenario, agricultural and forestry waste may not be merely charred as a mechanism of disposal but used for energy production (Section 2.4). This strategy is ecologically and economically attractive given the fact that energy is produced at the same time as bio-char is produced equivalent to the amount that can be achieved by direct charring.

Not all agricultural waste materials are suitable to produce bio-char, including many field or vegetable crop residues with the notable exception of rice husks 
(FFTC 2001), which has high concentrations of silica entrapping C during combustion (Raveendran et al. 1995). Rice husks are typically regarded as a waste product, but can be used to sequester $\mathrm{C}$ by producing bio-char. Global rice paddy production is $0.589 \mathrm{Pg} \mathrm{yr}^{-1}$. From this we calculate the sequestration potential to be $0.038 \mathrm{Pg} \mathrm{C} \mathrm{yr}^{-1}$ (calculated estimating $32 \%$ husk, 38\% C concentration, and $53.5 \%$ conversion from husk $\mathrm{C}$ to bio-char $\mathrm{C}$ ). Other crop residues such as nut shells (e.g., groundnut, hazelnut, macadamia nut, walnut, chestnut, coconut) but also bagasse from sugar cane processing, olive or tobacco waste are suitable and are in some locations available in large quantities. For example, groundnut shells are highly suitable for bio-char production and a global groundnut production of $0.036 \mathrm{Pg} \mathrm{yr}^{-1}$ (FAO 2004) would yield $0.002 \mathrm{Pg} \mathrm{C} \mathrm{yr}^{-1}$ of bio-char (30\% shell; UN/ECE 1995; other data taken from above). Very different opportunities arise depending on the location and the specific crop residues that are available.

The global amount of urban wastes can only be estimated. Reported values for the U.S. of 36.9 Tg (Walsh et al. 1999) suggest a bio-char sequestration potential of $0.01 \mathrm{Pg} \mathrm{yr}^{-1}$ and global bio-char yields from urban waste may therefore be estimated at $0.03 \mathrm{Pg} \mathrm{yr}^{-1}$. Together, the listed biomass wastes have the potential to produce $0.16 \mathrm{PgC}^{-1}$ (Table I). Actual values including all possible waste materials not listed here may be significantly higher. The calculated amount is a significant flux of $3 \%$ of emissions from fossil fuels and $10 \%$ of landuse change, but alone does not significantly affect the global $\mathrm{C}$ balance under the current scenarios (Figure 2B). The numbers for this sequestration option may not increase in the future, as production systems are increasingly optimized and less waste material accumulates.

\subsection{RENEWABLE FUELS FROM BIOMASS ENERGY}

Renewable fuels (bio-fuels, made from "modern biomass" in comparison to traditional biomass energy) have been increasingly investigated regarding their potential to provide energy for domestic and industrial purposes (Berndes et al. 2003; UNDP 2004). Renewable fuels yield a large proportion of renewable energy today (UNDP 2004). The underlying principle is usually the sustainable land-based production of an energy crop or the use of waste biomass and the conversion into bio-fuels by various mechanisms. Possible avenues for producing bio-fuels from biomass are ethanol production through microbial fermentation, extraction of oils from crops, pyrolysis and gasification of biomass. In the context of bio-char sequestration, only pyrolysis is of interest as it yields a bio-char residue. The two main approaches for pyrolysis are the production of bio-oil or hydrogen as the energy carrier, with biooil being the more advanced and more wide-spread technology. The feedstock is in principle similar to the one described for making bio-chars from waste materials (Section 2.3), and may include a wide variety of biomass (Yaman 2004) such as wood chips or pellets, bark, crop residues such as nut shells or rice husks, and grass residues such as bagasse from the sugarcane industry. Other sources are planted 
energy crops with the sole purpose of producing bio-fuels, such as short rotation woody plants or grasses (Section 2.5).

As an example for integrating bio-fuel and bio-char, we discuss a recent proposal for the production of hydrogen through steam reforming of pyrolysis gas and liquids, in conjunction with the production of bio-char for the purpose of land application (Day et al. 2005). About $48 \%$ of the initial C is not completely combusted to produce energy but left to produce a bio-char product. With a pyrolysis system for the production of bio-oil, a recovery of $42 \%$ (www.renewableoil.com), 30\% (Zabaniotou 1999) or 44-25\% (for wood and bagasse, respectively; www.dynamotive.com) of initial $\mathrm{C}$ in bio-char is commonly achieved in commercial facilities, assuming $45 \%$ $\mathrm{C}$ in feedstock and 75.7\% $\mathrm{C}$ in bio-char (Lehmann et al. 2002).

The pyrolysis temperature typically changes the yield of bio-fuels and bio-char as well as the properties of bio-char (the latter is discussed in Section 4). With increasing temperature, the recovery of bio-char commonly decreases whereas the C concentration increases (Daud et al. 2001; Demirbas 2001 2004a; Katyal et al. 2003). This leads to only a slightly lower $C$ recovery in bio-char as pyrolysis temperatures increase (Figure 3). The temperature dependency above $350^{\circ} \mathrm{C}$ is low, since the weight loss is compensated by an almost equivalent increase in $\mathrm{C}$ concentration. Therefore, pyrolysis temperature does not significantly affect $\mathrm{C}$ sequestration balances. More important than temperature for $\mathrm{C}$ yields in bio-char was the type of biomass used for pyrolysis. Greater concentrations of lignin increased $\mathrm{C}$ recovery (Figure 3) as well as did higher mineral content (Ravendraan et al. 1995; Nik-Azar et al. 1997). However, temperature affects yields and heating values of

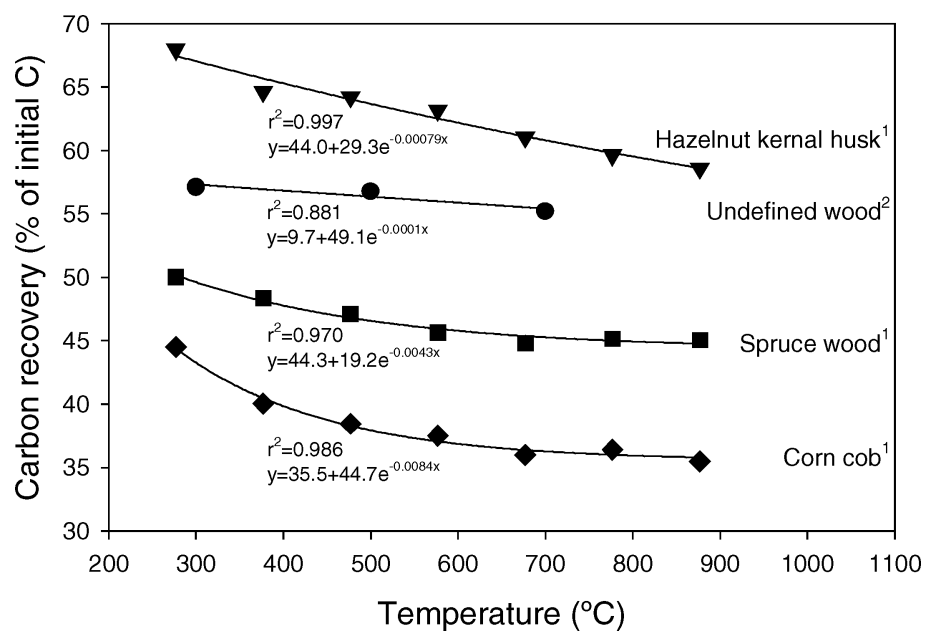

Figure 3. Carbon recovery in bio-char with increasing temperature using pyrolysis of different types of biomass. ${ }^{1}$ From Demirbas (2001) (total C determined by ASTM D1103-80 standard; biomass was ground to pass $0.2 \mathrm{~mm}$, pyrolysis was performed in vacuum); ${ }^{2}$ From FAO (1983) (values were given as typical values for bio-char kilns). 
bio-oil, which are highest between 470 and $490^{\circ} \mathrm{C}$ (Sensöz and Can 2002; Demirbas 2004b; www.dynamotive.com). Other factors that decrease bio-char yields are higher sweep gas flow (Katyal et al. 2003), smaller particle sizes (Zanzi et al. 2002), and higher heating rates (Demirbas 2004b).

With an additional process of removing $\mathrm{CO}_{2}$ from flue-gas ( $\mathrm{Li}$ et al. 2003) and the production of $\mathrm{NH}_{4} \mathrm{HCO}_{3}$ in an exothermic reaction, it is possible to strip $\mathrm{NOx}$ and SOx and increase the sequestered $\mathrm{C}$ by an additional 29\%. The result is a removal of $112 \mathrm{~kg}$ of $\mathrm{CO}_{2}(30.6 \mathrm{~kg} \mathrm{C})$ for each GJ of energy produced (Day et al. 2005; assuming that only $50 \%$ of the $\mathrm{HCO}_{3}{ }^{-}$will remain in soil on a global scale). The final product not only sequestered more $\mathrm{C}$ but also contained about $10 \% \mathrm{~N}$. The fertilizer use efficiency of this N-rich bio-char has not yet been sufficiently tested. If it is possible to substitute existing production of $\mathrm{N}$ fertilizers with this approach, the potential emission reductions of greenhouse gases is even greater. The $\mathrm{N}$ enrichment would also provide a financial incentive for land application substituting conventional $\mathrm{N}$ fertilizer applications. An economic benefit through bio-char application to soil in addition to the $\mathrm{C}$ sequestration is important as modern pyrolysis facilities use the bio-char to pre-dry the feedstock or to sell as fuel.

In order to obtain a true picture of the $\mathrm{C}$ budget of a modern biomass energy system using pyrolysis, a life-cycle analysis approach is required. For example greenhouse gas emissions that are associated with the production of the biomass have to be considered, as do the transportation, and the energy consumption during pyrolysis which may partially offset the reductions in global warming potential associated with the bio-char sequestration. These emissions are small, however, particularly, since predominantly waste biomass is used or bioenergy crops (e.g. willow; Volk et al. 2004) that require very little or no fertilizer additions in contrast to ethanol, where high $\mathrm{N}$ fertilization of maize or sugar cane contributes to significant global warming potential (Pimentel et al. 2002).

However such calculations are complex and must also capture the additional beneficial impacts of bio-char use; emissions of greenhouse gases such as nitrous oxide or methane which have shown to be reduced by bio-char application to soil (Section 5) as well as $\mathrm{C}$ that is sequestered in soil through the growth of energy crops (Lemus and Lal 2005), if degraded land were to be converted (Freibauer et al. 2004). A full assessment including emissions of other greenhouse gases and emissions of $\mathrm{CO}_{2}$ associated with the energy production has still to be undertaken.

The global importance of a bio-char sequestration as a byproduct of the conversion of biomass to bio-fuels through pyrolysis is difficult to predict, but is potentially very large. Modern biomass energy is the largest renewable energy supplier (68\% of all renewable energies) with 6 EJ in 2001 (UNDP 2004). If modern biomass energy were to be produced entirely by pyrolysis, $0.18 \mathrm{Pg} \mathrm{C}$ could be sequestered each year, using an equivalent production of bio-char of $30.6 \mathrm{~kg} \mathrm{C}$ for each GJ of energy quoted above (assuming no other greenhouse gas emissions or reductions). Presently, biofuel production using pyrolysis constitutes a small proportion compared to all modern biomass energies (UNDP 2004) and is only now being 
developed for more wide-spread adoption (www.iea.org; Meier and Faix 1999), but has great potential to generate electricity at a profit in the long term, and at a lower cost than any other biomass-to-electricity system (Bridgwater et al. 2002).

For 2100, Berndes et al. (2003) compiled the results of available data on the projected contribution of global modern biomass energy supply of $180-310 \mathrm{EJ} \mathrm{yr}^{-1}$. The projected amount of renewable fuels would potentially yield an amount of sequestered bio-char of 5.5-9.5 $\mathrm{Pg} \mathrm{Cyr}^{-1}$, if pyrolysis were to be used. A portion of today's biofuel through pyrolysis is produced from black liquor which is a byproduct from wood pulping in the papermaking industry and is not suitable for the production of bio-char. The calculated sequestration values are significant options compared to the anthropogenic changes in global $\mathrm{C}$ fluxes (Figure 2). The maximum potential sequestration of $9.5 \mathrm{Pg} \mathrm{C} \mathrm{yr}^{-1}$ would exceed today's anthropogenic emissions from fossil fuels of 5.4 $\mathrm{Pg} \mathrm{C} \mathrm{yr}^{-1}$ (Figure 2B) even if no fossil fuels are substituted by renewable fuels in the future. Whether any emissions of fossil fuel would be substituted by renewable fuels in the future can not be resolved here (-nd in Figure 2B).

\subsection{CROPPING FOR BIO-CHAR}

Land-based production of biomass for the sole purpose of producing bio-char as a means to reducing atmospheric $\mathrm{CO}_{2}$ is technically feasible and potentially of great quantitative importance (Seifritz 1993). However, high production costs may not justify both the improvement of soil fertility and the revenues that can be achieved through $C$ trading. It can be assumed that any bio-char system will be integrated into an existing land-based production system and add value to it. The most promising strategy for cropping of biomass as feedstock for bio-char production is the concurrent production of bio-fuels by pyrolysis.

At present, a variety of different crops are being tested with respect to the suitability as modern biomass energy crops, such as short-rotation woody plants (e.g. willow, Volk et al. 2004), grasses (e.g. Miscanthus spp., Clifton-Brown et al. 2004), and herbaceous plants (Kamm 2004). Two main criteria are important for their selection, high biomass production per unit area and suitability for producing energy (including various criteria that can not be reviewed here). With respect to the production of bio-char as a soil amendment, also the properties of the biochar obtained through pyrolysis have to be considered such as stability against decomposition (Section 4), efficiency to improve soil fertility, and ability to provide other ecosystem services (Section 5).

An important demand for the biomass cropping is the sustainability of the production system (Volk et al. 2004). While the withdrawals of nutrients are probably small (Volk et al. 2004) and the soil C contents will rather increase than decrease under most scenarios (Llemus and Lal 2005), soil fertility depletion can be an issue and has been the justification to fertilize bioenergy plantations with the ash from the combustion residue (Park et al. 2005). A return of bio-char may not only return 
the nutrients but also improve nutrient retention and sustainability of the biomass production system.

While the global potential for modern biomass production for biofuel is large and ever increasing, there is only a finite area of land available without compromising food production (Nonhebel 2005). This has to be considered for developing strategies for biofuel and bio-char production through biomass plantations and for the projections of future adoption. The order of magnitude of estimates used in the calculations above (Section 2.4) are not high enough to compromise other land use for example for food production. On the contrary, some regions especially in industrialized countries have large areas of idle and unused fields that can be used for modern biomass and consecutively biofuel and possible bio-char production (Fischer et al. 2005). These new cropping strategies for fuel provide important opportunities for farmers and rural populations to enter new markets. If linked to bio-char sequestration, these opportunities would even improve production of biomass and other environmental services (Section 5).

\section{How Much Bio-Char Can Soil Tolerate?}

How much bio-char can be applied before crop and timber yields decline or serious environmental threats occur? This is an important question in the light of maximizing the terrestrial $\mathrm{C}$ sink and in the light of possible revenues from $\mathrm{C}$ trading mechanisms discussed below. In some instances soils with very high bio-char concentrations have been found, which show close to $40 \%$ of its soil organic $\mathrm{C}$ to be what the cited authors call black C or charcoal (Glaser et al. 2001; Skjemstad et al. 2002). Especially in the case of Amazonian Dark Earths, high black C concentrations did not decrease but rather increased soil productivity (Lehmann et al. 2003b). Most of the results of deliberate bio-char additions to soil showed increasing crop yields with increasing additions up to very high loadings of $140 \mathrm{Mg} \mathrm{Cha}^{-1}$ (Lehmann and Rondon 2005). Some experiments show decreasing biomass production and crop yields at high concentrations. For example, beans (Phaseolus vulgaris L.) grown with bio-char additions of $60 \mathrm{Mg} \mathrm{Cha}^{-1}$ exhibit yields similar to control plants without bio-char additions (Rondon et al. 2004). From the data available to date, it appears that crops respond positively to bio-char additions up to $50 \mathrm{Mg} \mathrm{Cha}{ }^{-1}$ and may show growth reductions only at very high applications. For most plant species and soil conditions, this maximum was not reached even with $140 \mathrm{Mg} \mathrm{Cha}^{-1}$.

Examining the total sequestration opportunities on a global scale (Figure 2), a maximum annual soil input of $0.58 \mathrm{Pg} \mathrm{C} \mathrm{yr}^{-1}$ could be achieved under present-day scenarios. While this is a significant sequestration of about $10 \%$ of anthropogenic emissions from fossil fuels, it is only a $0.039 \%$ increase of total global soil C stocks per year or $3.9 \%$ during the coming 100 years. Concerning possible negative impacts of bio-char on soil ecosystem functions, this is an insignificant increase 
and, on the contrary, such an increase has potential positive effects on soil productivity (Lehmann and Rondon 2005). Assuming large bio-char sequestration over long periods of time, a bio-char sequestration of $140 \mathrm{Mg} \mathrm{Cha}^{-1}$ would calculate to $224 \mathrm{Pg} \mathrm{C}$ storage capacity globally for the 1,600 Mha of cropland worldwide and to $175 \mathrm{Pg} \mathrm{C}$ storage capacity globally for the $1,250 \mathrm{Mha}$ of temperate grasslands (IPCC 2000), not including forest land. These total sequestration opportunities are high and approach levels for total $\mathrm{C}$ in plants.

\section{How Stable Is Bio-Char?}

The longevity of bio-char in ecosystems is an important question since only a long half life will ensure a relevant sequestration. The stability and recalcitrance of bio-char against biotic and abiotic oxidation is as variable as the properties and origin of bio-char itself as discussed for black $\mathrm{C}$ sources (Schmidt and Noack 2000; Masiello 2004). Although black C in general is presumably very stable, Shnour (1966) reported a significant oxidation of graphite (the most stable form of black C) by microorganisms. Therefore, decomposition also of bio-chars can be expected. Experimental results are contradictory, and both rapid (Bird et al. 1999) and slow (Shindo 1991) decomposition of biomass-derived black $C$ was reported.

Notwithstanding the remaining uncertainty about its precise turnover, black $\mathrm{C}$ has been found to be the oldest fraction of $\mathrm{C}$ in soil, older than the most protected $\mathrm{C}$ in soil aggregates and organo-mineral complexes (Pessenda et al. 2001), which is commonly the most stable $\mathrm{C}$ in soil. This indicates that in quantitative terms biochar is stable, with decomposition leading to subtle, and possibly important changes in the bio-chemical form of the material rather than to significant mass loss.

Stability of bio-char critically depends on the production procedure. Kawamoto et al. (2005) found greater stability of charcoal produced at $400{ }^{\circ} \mathrm{C}$ than $1000^{\circ} \mathrm{C}$ against oxidation by ozone, despite the fact that aromaticity of bio-char significantly increases above a temperature of $700^{\circ} \mathrm{C}$ (Nishimiya et al. 1998). Apart from this abiotic oxidation, microbial decomposition of bio-chars is an important process in soil that may be influenced by charring temperature. Baldock and Smernik (2002) showed that $\mathrm{C}$ remaining in a bio-char-sand mixture significantly increased for biochars produced at $200^{\circ} \mathrm{C}$ or higher, while aromatic $\mathrm{C}$ structures determined by ${ }^{13} \mathrm{C}$ NMR increased at $250^{\circ} \mathrm{C}$ or higher. Whether oxidation in soil will follow a similar pattern, can not be resolved at this point. For example, labile organic matter in soil could accelerate microbial decomposition of bio-chars as shown by Hamer et al. (2004) with glucose. On the other hand, aggregation and physical protection of black $\mathrm{C}$ particles may reduce its mineralization. Some indication for the formation of clay-black C complexation was found in Chernozems (Brodowski et al. 2005) and Anthrosols (Glaser et al. 2000) by energy-dispersive X-ray spectroscopy. However, Rumpel et al. (2005) did not find an association between black $\mathrm{C}$ and minerals determined by $\mathrm{C}$ loss using HF treatment. An additional mechanism of physical 
stabilization of bio-char could be aggregation. Brodowski (2004) found a significant enrichment of black $\mathrm{C}$ within aggregates. It can be hypothesized that the presence of bio-char in soils actively promotes the formation of aggregates through a greater abundance of fungal hyphae. Bio-char is able to serve as a habitat for extraradical fungal hyphae that sporulate in their micropores due to lower competition from saprophytes (Saito and Marumoto, 2002). Further research is needed to resolve the stabilization and decomposition mechanisms of bio-char in soil.

Additionally, the decomposition of bio-chars is most likely reduced when it is transported down in the soil profile or buried in river, lake, or sea sediments. Very little is known about the transport mechanisms and the first analyses of black $\mathrm{C}$ in dissolved organic matter that could potentially leach into the deep soils, were only done recently (Kim et al. 2004). The average age of black C buried in deep sea sediments, for example, was found to be up to 13,900 years greater than the age of other organic $\mathrm{C}$ such as humic substances (Masiello and Druffel 1998). Time scales for sequestration into the 10s of thousands of years can be regarded as a permanent sink of atmospheric $\mathrm{CO}_{2}$.

\section{Other Environmental Effects of Bio-Chars in Soil}

Apart from the beneficial effects of drawing $\mathrm{CO}_{2}$ from the atmosphere, bio-char applications to soil are also able to reduce the emissions of other greenhouse gases. Rondon et al. (2005) found a virtually complete suppression of methane emissions at bio-char additions of $20 \mathrm{~g} \mathrm{~kg}^{-1}$ soil. Nitrous oxide emissions were reduced by up to $50 \%$ when bio-char was applied to soybean and by $80 \%$ in grass stands. These low emissions may be explained by better aeration (less frequent occurrence of anaerobic conditions) and possibly by greater stabilization of $\mathrm{C}$. The lower nitrous oxide evolution may also be an effect of slower $\mathrm{N}$ cycling (possibly due to a higher $\mathrm{C} / \mathrm{N}$ ratio).

In addition to reducing greenhouse gas emissions, bio-char applications to soil have the potential to decrease environmental pollution. Black $\mathrm{C}$ in soil similar to bio-chars efficiently adsorbs ammonia $\left(\mathrm{NH}_{3}\right)$ (e.g., Oya and Iu 2002; Iyobe et al. 2004) and acts as a buffer for ammonia in soil, therefore having the potential to decrease ammonia volatilization from agricultural fields. Biological immobilization of inorganic $\mathrm{N}$ also aids in retaining $\mathrm{N}$ and in decreasing ammonia volatilization, due to the low $\mathrm{N}$ concentrations and high $\mathrm{C} / \mathrm{N}$ ratios of biochars (Lehmann and Rondon 2005). Further, bio-chars are very efficient adsorbers for dissolved ammonium (Lehmann et al. 2002), nitrate (Mizuta et al. 2004), phosphate (Beaton et al. 1960), and other ionic solutes (Radovic et al. 2001) as well as hydrophobic organic pollutants (Gustaffson et al. 1997; Accardi-Dey and Gschwend 2002). No information exists at present whether this adsorption behavior would translate into a significant reduction of non-point source pollution of ground and surface waters by fertilizers or other pollutants in agricultural watersheds. 
Such effects of bio-chars on leaching and runoff losses of solutes require further research.

The combination of returning bio-chars with high $\mathrm{C} / \mathrm{N}$ ratios and abiotic buffering of mineral $\mathrm{N}$ may in some situations lead to low $\mathrm{N}$ availability to crops (Lehmann and Rondon 2005). In experiments in northern Sweden, however, increased nitrification and decreased ammonification was found after the addition of activated $\mathrm{C}$ to a pine forest (Berglund et al. 2004). It appears that the effects of bio-char on $\mathrm{N}$ dynamics in soils is not entirely understood. In a greenhouse study in Colombia, leguminous plants were able to compensate for low $\mathrm{N}$ availability with increased biological $\mathrm{N}_{2}$ fixation which is actually stimulated by bio-char additions (Rondon et al. 2004). Non-legumes, however, may require additional $\mathrm{N}$ fertilization to compensate for the immobilization. This is an undesirable effect as more $\mathrm{N}$ applications require more production of $\mathrm{N}$ fertilizers which is very energy-demanding (West and Marland 2002). Three solutions are possible which are not mutually exclusive: (i) bio-chars are only applied to leguminous plants until sufficient $\mathrm{N}$ has built up to allow economically satisfactory production of non-legumes without a net increase of $\mathrm{N}$ fertilization; (ii) bio-chars are fortified with $\mathrm{N}$ for example in a composting step or during the production of bio-char in an energy production process (Lee and Li 2003); (iii) the amounts of applied bio-char are adjusted at a sufficiently low level to allow for $\mathrm{N}$ to accumulate and plant productivity to optimize.

The environmental benefits of bio-char applications other than $\mathrm{C}$ sequestration are still poorly quantified externalities. No mechanism exists at this point that would enable the land user to benefit financially from the reduced off-site pollution resulting from bio-char applications.

\section{Implications of Bio-Char for Carbon Emissions Trading}

The foregoing discussion raises interesting questions. We have summarized and reviewed new knowledge on the potential for bio-char management in a number of situations and have considered, or at least inferred, a number of different systems which may deliver benefits in terms of improved agricultural and environmental performance. We have indicated that the socio-economic aspects of the opportunities are poorly understood. But we have also indicated that in some situations the required adaptation or change in agricultural practice is as yet small. However, whilst some financial benefits of the technologies considered may be obvious and lead to adoption in the future, the context of this paper is set by wider environmental concerns, in this case climate change.

A key challenge that exists is how to encourage a change in practice that leads to a wider environmental benefit. Policy instruments such as subsidies, technology standards etc may be used to bring about change. However, we do not attempt to examine the relative merits of contrasting approaches. Rather we specifically consider the existing mechanism of $\mathrm{C}$ emissions trading. 
The Kyoto protocol represents an existing example of a policy instrument, that is envisaged will lead to a change in practice. In December 1997, the parties to the 1992 United Nations Framework Convention on Climate Change (UNFCCC) adopted the Kyoto Protocol (http://unfccc.int/resource/convkp.html\#kp). The Kyoto Protocol creates obligations for 38 industrialized countries, termed Annex I countries, to return their emissions of greenhouse gases to an average of approximately five percent below their 1990 levels over the period from 2008-2012. Under Kyoto both "Policies and Measures" - actions taken directly by government agencies that have the effect of reducing emissions as well as "Sinks Enhancement" - drawing $\mathrm{CO}_{2}$ out of the air and into biomass and soil are proposed as mechanisms to reduce greenhouse gas levels in the atmosphere.

Although sink enhancement ( $\mathrm{C}$ sequestration) is intended as a mechanism to off-set greenhouse gas emissions under the Kyoto Protocol, the only forms of $\mathrm{C}$ sequestration so far allowable through the trading programs established under $\mathrm{CDM}^{1}$ are in situations where $\mathrm{C}$ is sequestered in newly afforested land. Neither avoided deforestation or $\mathrm{C}$ sequestration in agricultural cropland are currently allowable.

In order to establish the tradable commodity the key factor to be considered is how the change of practice leads to a reduction in greenhouse gas emissions. For example, under a current practice of complete combustion (burning) more than $90 \%$ of the $\mathrm{C}$ in an organic material is oxidized to form $\mathrm{CO}_{2}$, whereas under the various systems of bio-char production discussed above only $45-48 \%$ of the organic $\mathrm{C}$ is oxidized to $\mathrm{CO}_{2}$. Consequently, by switching from burning of residues to a biochar system $420-450 \mathrm{~kg} \mathrm{C}$ of emissions per ton of $\mathrm{C}$ used as feedstock are avoided. Further, the energy produced, if used to displace energy produced by fossil fuel burning, leads to a further reduction in emissions. These avoided emissions, rather than sequestered $\mathrm{C}$, are the tradable entities under the current CDM rules.

The avoided emissions for the changes in practice considered earlier are shown in Table II. In all instances we use data from Day et al. (2005) for the pyrolysis system to produce energy and bio-char. From this it can be seen that for every $\mathrm{Mg}$ of $\mathrm{C}$ used for energy production by pyrolysis the avoided emissions range from $-0.5-2.4 \mathrm{Mg} \mathrm{CO}_{2}$ per $\mathrm{Mg} \mathrm{C}$ as feedstock used in the pyrolysis process (i.e. $-14 \%$ to $65 \%$ ). The negative values arise because energy is released more efficiently when wood is burned directly for energy production. However, this direct burn loses the added environmental benefits of applying bio-char to soil.

From the earlier technical discussion it is clear that systems that sequester biochar can be distinguished from other strategies for soil C sequestration previously considered for agriculture, because (i) it is clearly established that bio-char sequestration represents long term storage of $\mathrm{C}$; and, (ii) the $\mathrm{C}$ added has distinct characteristics enabling verification of sequestration, if required.

Given that avoided emissions are already a 'tradable' component, it is necessary only to demonstrate that the bio-char residue is not broken down further to release greenhouse gases when added to soil (or otherwise utilized). This is an important assumption, which has stimulated considerable debate around technical aspects of 


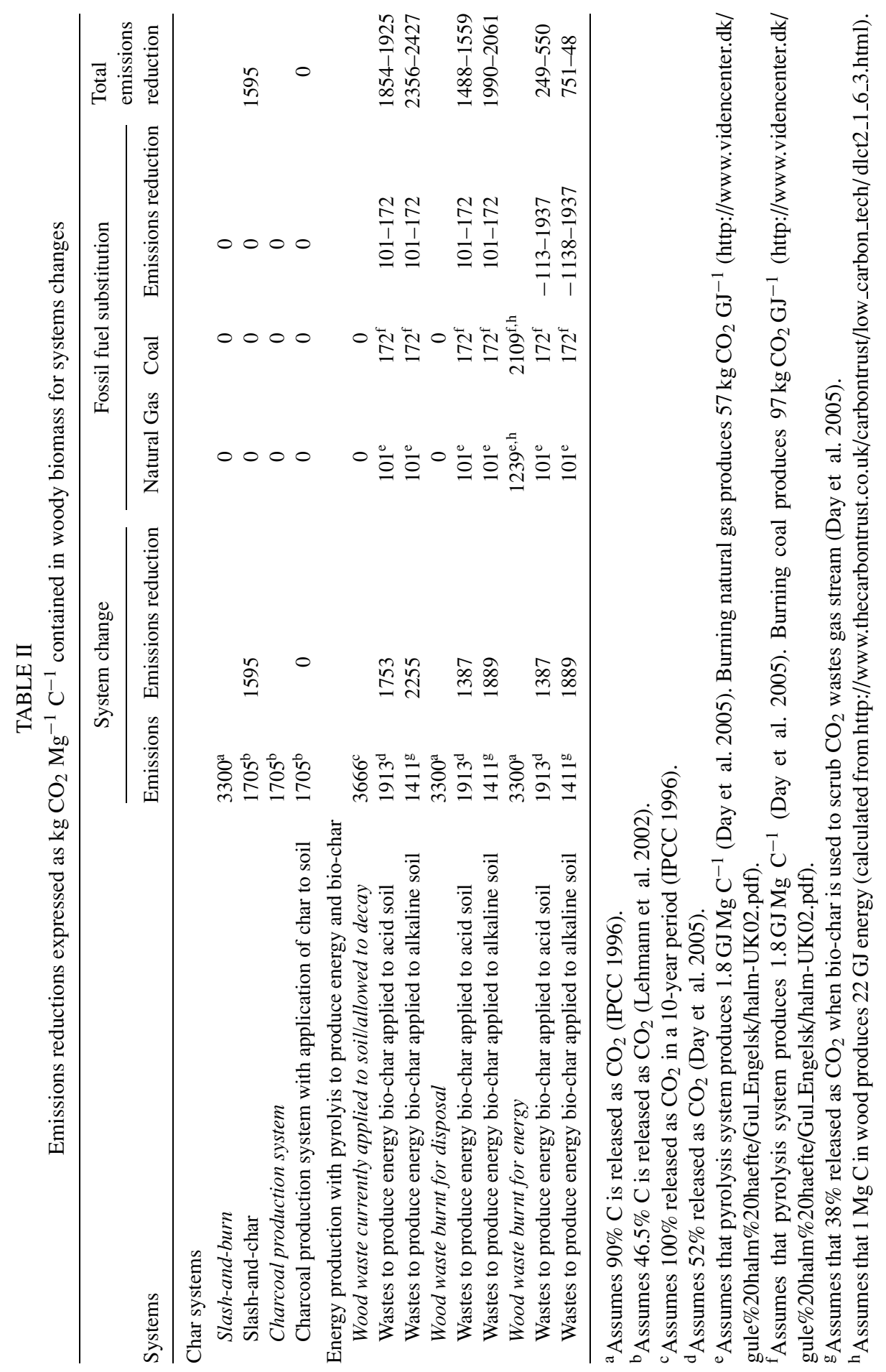


soil $\mathrm{C}$ sequestration, such as (i) 'permanency' i.e. ensuring that $\mathrm{C}$ sequestered in soil is not released by a subsequent change in practice; and, (ii) measurement and monitoring of $\mathrm{C}$ sequestration in soil. For example, some have argued strongly for the promotion of zero-tillage or conservation agriculture as a strategy to sequester soil C. However others (Smith et al. 2001) caution that after accounting for increased nitrous oxide emissions the reductions may be small. Perceptions of risk associated with soil $\mathrm{C}$ sequestration also lead to the value of $\mathrm{C}$ being discounted.

From this brief consideration it can be appreciated that differentiating between situations where the proposed trading route represents soil $\mathrm{C}$ sequestration as opposed to avoided emissions is important in terms of designing appropriate $\mathrm{C}$ emissions trading projects. Recognising that reduced emissions are a primary objective it is reasonable to ask, why bio-char produced in slash-and-char systems should not be used as fuel - maximizing the 'avoided emissions' (as in the case of 'The Plantar Project' mentioned earlier). We can answer this question in two ways, (i) bio-char use only becomes tradable under current $\mathrm{C}$ emission trading schemes if the energy produced substitutes for, or slows the rate of switch to, fossil fuel use. In many rural situations, however, where charcoal may be produced and used, fossil fuel substitution is unlikely to arise; and, (ii) preliminary results suggest benefits both in terms of agricultural production and wider environmental benefits from application to soil. This second point does, however, point to an interesting challenge and to a need to examine the socio-economic aspects. Particularly the trade-offs involved in different situations, warrant further exploration.

A particular challenge exists to find simple ways to realize the benefits to the soil and wider environment achieved through the amendment of soil with biochar, which may not be achieved by maximizing the reduction of $\mathrm{C}$ emissions. Strategies such as producing bio-char, while producing energy from renewable fuels may offer a potential way forward. This potentially attractive combination means consumers can participate in active $\mathrm{C}$ sequestration by using energy produced with the renewable and sustainable bio-char technology.

\section{Note}

1. Clean Development Mechanism (CDM) - Article 12 of the Kyoto Protocol grants Annex I parties the right to generate or purchase emission reduction credits from projects undertaken by them within non-Annex I countries.

\section{References}

Accardi-Dey, A. and Gschwend, P.M.: 2002, 'Assessing the combined roles of natural organic matter and black carbon as sorbents in sediments', Environmental Science and Technology 36, 21-29.

Bailis, R., Ezzati, M. and Kammen, D.M.: 2005, 'Mortality and greenhouse gas impacts of biomass and petrolium energy futures in Africa', Science 308, 98-103. 
Batjes, N.H.: 1998, 'Mitigation of atmospheric $\mathrm{CO}_{2}$ concentrations by increased carbon sequestration in the soil', Biology and Fertility of Soils 27, 230-235.

Beaton, J.D., Peterson, H.B. and Bauer, N.: 1960, 'Some aspects of phosphate adsorption by charcoal', Soil Science Society of America Proceedings 24, 340-346.

Berglund, L.M., DeLuca, T.H. and Zackrisson, O.: 2004, 'Activated carbon amendments to soil alters nitrification rates in Scots pine forests', Soil Biology and Biochemistry 36, 2067-2073.

Berndes, G., Hoogwijk, M. and van den Broeck, R.: 2003, 'The contribution of biomass in the future global energy supply: A review of 17 studies', Biomass and Bioenergy 25, 1-28.

Bird, M.I., Moyo, C., Veendaal, E.M., Lloyd, J. and Frost, P.: 1999, 'Stability of elemental carbon in a savanna soil', Global Biogeochemical Cycles 13, 923-932.

Bridgwater, A.V., Toft, A.J. and Brammer, J.G.: 2002, 'A techno-economic comparison of power production by biomass fast pyrolysis with gasification and combustion', Renewable and Sustainable Energy Reviews 6, 181-246.

Briggs, D.G.: 1994, Forest Products Measurements and Conversion Factors: With Special Emphasis on the U.S. Pacific Northwest, Institute of Forest Resources, Contribution 75, University of Washington: Seattle, WA.

Brodowski, S.B.: 2004, Origin, Function, and Reactivity of Black Carbon in the Arable Soil Environment, Ph.D. Dissertation, Institute of Soil Science and Soil Geography, Bayreuth, University of Bayreuth.

Brodowski, S., Amelung, W., Haumeier, L., Abetz, C. and Zech, W.: 2005, 'Morphological and chemical properties of black carbon in physical soil fractions as revealed by scanning electron microscopy and energy-dispersive X-ray spectroscopy', Geoderma, in press, DOI: 10.1016/j.geoderma.2004.12.019.

Clifton-Brown, J.C., Stampfl, P.F. and Jones, M.B.: 2004, 'Miscanthus biomass production for energy in Europe and its potential contribution to decreasing fossil fuel carbon emissions', Global Change Biology 10, 509-518.

Coomes, O.T. and Burt G.J.: 2001, 'Peasant charcoal production in the Peruvian Amazon: rain forest use and economic reliance', Forest Ecology and Management 140, 39-50.

Daud, W.M.A.W., Ali, W.S.W. and Sulaiman, M.Z.: 2001, 'Effect of carbonization temperature on the yield and porosity of char produced from palm shell', Journal of Chemical Technology and Biotechnology 76, 1281-1285.

Day, D., Evans, R.J., Lee, J.W. and Reicosky, D.: 2005, 'Economical $\mathrm{CO}_{2}, \mathrm{SO}_{x}$, and $\mathrm{NO}_{x}$ capture from fossil-fuel utilization with combined renewable hydrogen production and large-scale carbon sequestration', Energy 30, 2558-2579.

Demirbas, A.: 2001, 'Carbonization ranking of selected biomass for charcoal, liquid and gaseous products', Energy Conversion and Management 42, 1229-1238.

Demirbas, A.: 2004a, 'Effects of temperature and particle size on bio-char yield from pyrolysis of agricultural residues', Journal of Analytical and Applied Pyrolysis 72, 243-248.

Demirbas, A.: 2004b, 'Determination of calorific values of bio-chars and pyro-oils from pyrolysis of beech trunkbarks', Journal of Analytical and Applied Pyrolysis 72, 215-219.

DOE: 1999, Carbon Sequestration Research and Development, Reichle, D., et al. (Eds.), U.S. Department of Energy, Office of Science, Washington DC, http://www.osti.gov/energycitations/ servlets/purl/810722-9s7bTP/native/

Erickson, C.: 2003, 'Historical ecology and future explorations', in J. Lehmann, D.C. Kern, B. Glaser and W.I. Woods (eds.), Amazonian Dark Earths: Origin, Properties, Management, (pp. 455-500) Dordrecht, Kluwer Academic Publishers.

FAO: 1983, Simple Technologies for Charcoal Making, Rome, Italy, Food and Agriculture Organization of the United Nations, Forestry Paper No. 41.

FAO: 1991, Charcoal Production and Pyrolysis Technologies, P. Thoresen (ed.), Rome, Italy, Food and Agriculture Organization of the United Nations. 
FAO: 2004, FAOSTAT Data, Rome, Italy, Food and Agriculture Organization of the United Nations, http://apps.fao.org/default.jsp.

FFTC: 2001, Application of Rice Husk Charcoal, Taipei, FFTC Leaflet for Agriculture, No. (4).

Fischer, G., Prieler, S. and van Velthuizen, H.: 2005, 'Biomass potentials of miscanthus, willow and poplar: results and policy implications for Eastern Europe, Northern and Central Asia', Biomass and Bioenergy 28, 119-132.

Freibauer, A., Rounsevell, M.D.A., Smith, P. and Verhagen, J.: 2004, 'Carbon sequestration in agricultural soils of Europe', Geoderma 122, 1-23.

Glaser, B., Balashov, E., Haumaier, L., Guggenberger, G. and Zech, W.: 2000, 'Black carbon in density fractions of anthropogenic soils of the Brazilian Amazon region', Organic Geochemistry 31, 669-678.

Glaser, B., Haumaier, L., Guggenberger, G. and Zech, W.: 2001, 'The Terra Preta phenomenon - A model for sustainable agriculture in the humid tropics', Naturwissenschaften $\mathbf{8 8}, 37-41$.

Glaser, B., Lehmann, J. and Zech, W.: 2002, 'Ameliorating physical and chemical properties of highly weathered soils in the tropics with charcoal-A review', Biology and Fertility of Soils 35, 219-230.

Gustaffson, Ö., Haghseta, F., Chan, C., Macfarlane, J. and Gschwend, P.M.: 1997, 'Quantification of the dilute sedimentary soot phase: Implications for the PAH speciation and bioavailability', Environmental Science and Technology 31, 203-209.

Hamer, U., Marschner, B., Brodowski, S. and Amelung, W.: 2004, 'Interactive priming of black carbon and glucose mineralization', Organic Geochemistry 35, 823-830.

Hughes, R.F., Kauffman, J.B. and Cummings, D.L.: 2000, 'Fire in the Brazilian Amazon: 3. Dynamics of biomass, $\mathrm{C}$ and nutrient pools in regenerating forests', Oecologia 124, 574-588.

IPCC: 1996, Revised 1996 IPCC Guidelines for National Greenhouse Gas Inventories, Greenhouse Gas Inventory Reference Manual Volume 3, J.T. Houghton, L.G. Meira Filho, B. Lim, K. Treanton, I. Mamaty, Y. Bonduki, D.J. Griggs and B.A. Callender (eds.), IPCC/OECD/IEA, Bracknell, UK, Meteorological Office.

IPCC: 2000, Land Use, Land-Use Change, and Forestry, Watson, R.T., Noble, R., Bolin, B., Ravindranath, N.H., Verardo, D.J. and Dokken, D.J. (eds.), Intergovernmental Panel on Climatic Change Special Report, Cambridge, Cambridge University Press.

IPCC: 2001, Climate Change 2001: The Scientific Basis, Technical Summary by Workgroup I of the Intergovernmental Panel on Climatic Change, Cambridge, UK, Cambridge University Press.

Iyobe, T., Asada, T., Kawata, K. and Oikawa, K.: 2004, 'Comparison of removal efficiencies for ammonia and amine gases between woody charcoal and activated carbon', J. Health Sci. 50, $148-153$.

Izaurralde, R.C., Rosenberg, N.J. and Lal, R.: 2001, 'Mitigation of climate change by soil carbon sequestration', Advances in Agronomy 70, 1-75.

Jenkinson, D.S. and Ayanaba, A.: 1977, 'Decomposition of carbon-14 labeled plant material under tropical conditions', Soil Science Society of America Journal 41, 912-915.

Kamm, J.: 2004, 'A new class of plants for a biofuel feedstock energy crop', Applied Biochemistry and Biotechnology 113-116, 55-70.

Katyal, S., Thambimuthu, K. and Valix, M.: 2003, 'Carbonisation of bagasse in a fixed bed reactor: influence of process variables on char yield and characteristics', Renewable Energy 28, 713-725.

Kawamoto, K., Ishimaru, K. and Imamura, Y.: 2005, 'Reactivity of wood charcoal with ozone', Journal of Wood Science 51, 66-72.

Ketterings, Q.M., Wibowo, T.T., van Noordwijk, M. and Penot E.: 1999, 'Farmers' perspectives on slash-and-burn as a land clearing method for small-scale rubber producers in Sepunggur, Jambi Province, Sumatra, Indonesia', Forest Ecology and Management 120, 157-169.

Kim, S., Kaplan, L.A., Benner, R. and Hatcher, P.G.: 2004, 'Hydrogen-deficient molecules in natural riverine water samples - evidence for the existence of black carbon in DOM', Marine Chemistry 92, 225-234. 
Lal, R.: 2004, 'Agricultural activities and the global carbon cycle', Nutrient Cycles in Agroecosystems 70, 103-116.

Lee, J.W. and Li, R.: 2003, 'Integration of coal-fired energy systems with $\mathrm{CO}_{2}$ sequestration through $\mathrm{NH}_{4} \mathrm{HCO}_{3}$ production', Energy Conversion and Management 44, 1535-1546.

Lehmann, J., da Silva Jr, J.P., Rondon, M., Cravo, M.S., Greenwood, J., Nehls, T., Steiner, C. and Glaser, B.: 2002, 'Slash-and-char - a feasible alternative for soil fertility management in the central Amazon?', Proceedings of the 17th World Congress of Soil Science, (pp. 1-12) Bangkok, Thailand. CD-ROM Paper no. 449.

Lehmann, J., da Silva Jr., J.P., Steiner, C., Nehls, T., Zech, W. and Glaser, B.: 2003a, 'Nutrient availability and leaching in an archaeological Anthrosol and a Ferralsol of the Central Amazon basin: fertilizer, manure and charcoal amendments', Plant and Soil 249, 343-357.

Lehmann, J., Kern, D.C., German, L.A., McCann, J., Martins, G.C. and Moreira, A.: 2003b, 'Soil Fertility and Production Potential', in J. Lehmann, D.C. Kern, B. Glaser and W.I. Woods (eds.), Amazonian Dark Earths: Origin, Properties, Management, (pp. 105-124) Dordrecht, Kluwer Academic Publishers.

Lehmann, J. and Rondon, M.: 2005, 'Bio-char soil management on highly-weathered soils in the humid tropics', in N. Uphoff (ed.), Biological Approaches to Sustainable Soil Systems, Boca Raton, CRC Press, in press.

Lemus, R. and Lal, R.: 2005, 'Bioenergy crops and carbon sequestration', Critical Reviews in Plant Sciences 24, 1-21.

Li, X., Hagaman, E., Tsouris, C. and Lee, J.W.: 2003, 'Removal of carbon dioxide from flue gas by ammonia carbonization in the gas phase', Energy \& Fuels 17, 69-74.

Liu, S., Kaire, M., Wood, E., Diallo, O. and Tieszen, L.L.: 2004, 'Impacts of land use and climate change on carbon dynamics in south-central Senegal', Journal of Arid Environments 59, 583604.

Malkow, T.: 2004, 'Novel and innovative pyrolysis and gasification technologies for energy efficient and environmentally sound MSW disposal', Waste Management 24, 53-79.

Marchetti, C.: 1977, 'Geo-engineering and $\mathrm{CO}_{2}$ problem', Climate Change 1, 59-68.

Masiello, C.A. and Druffel, E.R.M.: 1998, 'Black carbon in deep-sea sediments', Science 280, 1911-1913.

Masiello, C.A.: 2004, 'New directions in black carbon organic geochemistry', Marine Chemistry 92 , 201-213.

Meier, D. and Faix, O.: 1999, 'State of the art of applied fast pyrolysis of lignocellulosic materials - a review', Bioresource Technology 68, 71-77.

Mizuta, K., Matsumoto, T., Hatate, Y., Nishihara, K. and Nakanishi T.: 2004, 'Removal of nitratenitrogen from drinking water using bamboo powder charcoal', Bioresource Technology 95, $255-257$.

Nik-Azar, M., Hajaligol, M.R., Sohrabi, M. and Dabir, B.: 1997, 'Mineral matter effects in rapid pyrolysis of beech wood', Fuel Processing Technology 51, 7-17.

Nishimiya, K., Hata, T. and Imamura, Y.: 1998, 'Analyses of chemical structure of wood charcoal by X-ray photoelectron spectroscopy', Journal of Wood Science 44, 56-61.

Nonhebel, S.: 2005, 'Renewable energy and food supply: Will there be enough land?' Renewable and Sustainable Energy Reviews 9, 191-201.

Nye, P.H. and Greenland, D.J.: 1960, The Soil under Shifting Cultivation. London, Commonwealth Bureau of Soils Technological Communication 51, 156p.

Okimori, Y., Ogawa, M. and Takahashi, F.: 2003, 'Potential of $\mathrm{CO}_{2}$ emission reductions by carbonizing biomass waste from industrial tree plantation in south Sumatra, Indonesia', Mitigation and Adaptation Straegies for Global Change 8, 261-280.

Oya, A. and Iu, W.G.: 2002, 'Deodorization performance of charcoal particles loaded with orthophosphoric acid against ammonia and trimethylamine', Carbon 40, 1391-1399. 
Palm, C., Alegre, J., Arevalo, L., Mutuo, P., Mosier, A., Coe, R. 2004. 'Nitrous oxide and methane fluxes in six different land use systems in Peruvian Amazon', Global Biogeochemical Cycles 16, 1073-1082.

Park, B.B., Yanai, R.D., Sahm, J.M., Lee, D.K. and Abrahamson, L.P.: 2005, 'Wood ash effects on plant and soil in a willow bioenergy plantation', Biomass and Bioenergy 28, 355-365.

PCF: 2003, 2003 PCF Annual Report, Prototype Carbon Fund, The World Bank, Washington DC.

Pessenda, L.C.R., Gouveia, S.E.M. and Aravena, R.: 2001, 'Radiocarbon dating of total soil organic matter and humin fraction and its comparison with ${ }^{14} \mathrm{C}$ ages of fossil charcoal', Radiocarbon 43, 595-601.

Pimentel, D., Herz, M., Glickstein, M., Zimmerman, M., Allen, R., Becker, K., Evans, J., Hussain, B., Sarsfeld, R., Grosfeld, A. and Seidel, T.: 2002, 'Renewable energy: current and potential issues', Bioscience 52, 1111-1120.

Post, W.M. and Kwon, K.C.: 2000, 'Soil carbon sequestration and land-use change: Processes and potential', Global Change Biology 6, 317-328.

Radovic, L.R., Moreno-Castilla, C. and Rivera-Utrilla, J.: 2001, 'Carbon materials as adsorbents in aqueous solutions', in L.R. Radovic (ed.), Chemistry and Physics of Carbon, (pp. 227-405) New York, Marcel Dekker.

Rasmussen, P.E., Goulding, K., Brown, W.T., Grace, J.R., Janzen, H.H. and Korschens, M.: 1998, 'Long-term agroecosystem experiments: Assessing agricultural sustainability and global change', Science 282, 893-896.

Raveendran, K., Ganesh, A. and Khilar, K.C.: 1995, 'Influence of mineral matter on biomass pyrolysis characteristics', Fuel 74, 1812-1822.

Richter, D.D., Markewitz, D., Trumbore, S.E. and Wells, C.G.: 1999, 'Rapid accumulation and turnover of soil carbon in a re-establishing forest', Nature 400, 56-58.

Rondon, M., Lehmann, J., Ramirez, J. and Hurtado, M.P.: 2004, 'Biologial nitrogen fixation by common beans (Phaseoulus vulgaris) increases with charcoal additions to soils', in Integrated Soil Fertility Management in the Tropics, (pp. 58-60) 2004 Annual Report of the TSBF Institute, CIAT, Cali, Colombia.

Rondon, M., Ramirez, J.A. and Lehmann, J.: 2005, 'Charcoal additions reduce net emissions of greenhouse gases to the atmosphere', in Proceedings of the 3rd USDA Symposium on Greenhouse Gases and Carbon Sequestration, Baltimore, USA, March 21-24 2005, p. 208.

Rumpel, C., Alexis, M., Chabbi, A., Chaplot, V., Rasse, D.P., Valentin, C. and Mariott, A.: 2005, 'Black carbon contribution to soil organic matter decomposition in tropical sloping land under slash-and-burn agriculture', Geoderma, in press, DOI: 10.1016/j.geoderma.2005.01.007.

Saito, M. and Marumoto. T.: 2002, 'Inoculation with arbuscular mycorrhizal fungi: The status quo in Japan and the future prospects', Plant and Soil 244, 273-279.

Schlesinger, W.H. and Lichter, J.: 1999, 'Limited carbon storage in soil and litter of experimental forest plots under incerased atmospheric $\mathrm{CO}_{2}$ ', Nature 411, 466-469.

Schlesinger, W.H.: 1990, 'Evidence from chronosequence studies for a low carbon storage potential of soils', Nature 348, 232-234.

Schlesinger, W.H.: 1999, 'Carbon and agriculture - Carbon sequestration in soils', Science 284, 2095.

Schmidt, M.W.I. and Noack, A.G.: 2000, 'Black carbon in soils and sediments: Analysis, distribution, implications, and current challenges', Global Biogeochemical Cycles 14, 777-794.

Scholes, R.J. and Noble, I.R.: 2001, 'Climate change - storing carbon on land', Science 294, 1012-1013.

Seifritz, W.: 1993, 'Should we store carbon in charcoal?', International Journal of Hydrogen Energy 18, 405-407.

Sensöz, S. and Can, M.: 2002, 'Pyrolysis of pine (Pinus bruta Ten.) chips: 1. effects of pyrolysis temperature and heating rate on the product yields', Energy Sources 24, 347-354. 
Shindo, H.: 1991, 'Elementary composition, humus composition, and decomposition in soil of charred grassland plants', Soil Science and Plant Nutrition 37, 651-657.

Shinogi, Y., Yoshida, H., Koizumi, T., Yamaoka, M. and Saito, T.: 2003, 'Basic characteristics of low-temperature carbon products from waste sludge', Advances in Environmental Research 7, 661-665.

Shneour, E.A.: 1966, 'Oxidation of graphite carbon in certain soils', Science 151, 991-992.

Skjemstad, J.O., Reicosky, D.C., Wilts, A.R. and McGowan, J.A.: 2002, 'Charcoal carbon in U.S. agricultural soils', Soil Science Society of America Journal 66, 1249-1255.

Smith, P., Goulding, K.W.T., Smith K.A., Powlson D.S., Smith J.U., Falloon P. and Coleman K.: 2001. 'Enhancing the carbon sink in European agricultural soils: including trace gas fluxes in estimates of carbon mitigation potential', Nutrient Cycling in Agroecosystems 60, 237-252.

Sombroek, W., Nachtergaele, F.O. and Hebel, A.: 1993, 'Amounts, dynamics and sequestering of carbon in tropical and subtropical soils', Ambio 22, 417-426.

Sombroek, W., Ruivo, M.L., Fearnside, P.M., Glaser, B. and Lehmann J.: 2003, 'Amazonian Dark Earths as carbon stores and sinks', in J. Lehmann, D.C. Kern, B. Glaser and W.I. Woods (eds.), Amazonian Dark Earths: Origin, Properties, Management, (pp. 125-139) Dordrecht, Kluwer Academic Publishers.

UN/ECE: 1995, Agricultural Statistics; Handbook; Geneva, Switzerland, United Nations Economic Commission for Europe.

UNDP: 2004, World Energy Assessment; ed. J. Goldemberg and T. B. Johansson, New York, NY, UNDP.

US Interagency Task Force on Tropical Forests: 1980, The World's Tropical Forests: A Policy, Strategy and Program for the United States, Dept. of State Publ. 9117: Washington, DC.

Volk, T.A., Verwijst, T., Tharakan, P.J., Abrahamson, L.P. and White, E.H.: 2004, 'Growing fuel: A sustainability assessment of willow biomass crops', Frontiers in Ecology and the Environment 2, 411-418.

Walsh, M.E., Perlack, R.L., Turhollow, A., Ugarte, D.T., Becker, D.A., Graham, R.L., Slinksy, S.E. and Ray, D.E.: 1999, Biomass Feedstock Availability in the United States: 1999 State Level Analysis, Oak Ridge National Laboratory: Oak Ridge, TN.

Weisbach, C., Tiessen, H. and Jimenez-Osornio, J.J.: 2002, 'Soil fertility during shifting cultivation in the tropical Karst soils of Yucatan', Agronomie 22, 253-263.

West, T.O. and Marland, G.: 2002, 'A synthesis of carbon sequestration, carbon emissions, and net carbon flux in agriculture: comparing tillage practices in the United States', Agriculture, Ecosystems and Environment 91, 217-232.

Yaman, S.: 2004, 'Pyrolysis of biomass to produce fuels and chemical feedstocks', Energy Conversion and Management 45, 651-671.

Zabaniotou, A.A.: 1999, 'Pyrolysis of forestry biomass by-products in Greece', Energy Sources 21, 395-403.

Zanzi, R., Sjöström, K. and Björnbom, E.: 2002, 'Rapid pyrolysis of agricultural residues at high temperature', Biomass and Bioenergy 23, 357-366. 